\title{
Gender and Age Group Differences in Stereotypes about Mental Health Care Providers
}

\author{
Ddoctoral student at the University of Latvia, Department of Psychology \\ Iklasma@gmail.com
}

Girts Dimdins, Ph.D.

Professor of Social Psychology at the University of Latvia, Department of Psychology

\section{Doi:10.5901/mjss.2013.v4n10p185}

\section{Abstract}

\begin{abstract}
Mental health care providers play a significant role in the prevention of mental health problems and promotion of well-being. The aim of the study was to explore gender and age group differences in stereotypes about helping professionals in the mental health care field. The data were derived from 338 Latvian-speaking adults aged 18 to 87 . They rated stereotypic characteristics of five typical helping professionals (a family doctor, a psychologist, a psychiatrist, a clergyman, and an astrologer) on a sevenpoint Likert-type scale. The stereotype content model was used to measure warmth and competence stereotypes (Fiske, Xu, Cuddy, \& Glick, 1999). Gender differences show that women rate a typical psychiatrist higher on warmth and four of five helping professionals higher on competence; the family doctor is an exception. Age group differences show that the older age group (aged 50 to 87) compared to the younger age group (aged 18 to 49) rate a psychiatrist and a psychologist lower on warmth and competence, but a family doctor - higher on competence. The findings are discussed in the terms of attitudes toward mental health care providers.
\end{abstract}

Keywords: stereotypes, mental health care providers.

\section{Introduction}

For nearly a century stereotypes have been a significant topic in social psychology. Many studies have been published in this field (e.g., Fiske, 2012; Plous, 2003; Sherman, 1996). Social stereotypes are defined as simplified and generalised beliefs about individuals or groups (Cox, Abramson, Devine, \& Hollon, 2012). Researchers have found that stereotypes affect attitudes, emotions, and behaviours (Cuddy, Fiske, \& Glick, 2007). For example, groups stereotyped as high on warmth elicit active facilitation - helping and protecting, but groups stereotyped as low on warmth elicit anger, fear and active harm; therefore, stereotypes about mental health providers are the theme of great importance. Mental health care providers are professionals who offer services to treat mental disorders and illnesses, to cope with problems and for improving mental health and well-being. They play a critical role in the protection and improvement of mental health. The aim of this research was to explore gender and age group differences in stereotypes about helping professionals in the mental health care field.

Researchers who studied profession stereotypes have concluded that even neutral job titles are related to stereotypes (Lipton, O'Connor, Terry, \& Bellamy, 1991). For example, certain occupations are associated with one or the other gender and/or certain ethnic group. These stereotypes usually are rooted in society beliefs, and are difficult to change. Generally, helping professions are related to warmth stereotype (see, Asuncion \& Mackie, 1996; Brambilla, Sacchi, Castellini, \& Riva, 2010; Sherman, 1996). For example, psychologists are perceived as warmer than engineers (Brambilla et al., 2010).

Research shows that the public attitude toward psychologists has improved over the years (von Sydow \& Reimer, 1998). In general, the profession is viewed positively, and psychologists are often described as caring, friendly, helpful, and good listeners (e.g., Farberman, 1997; Firmin et al., 2012; Wollersheim \& Walsh, 1993). Despite this tendency, there are still certain problems concerning public perceptions, that is, the lack of understanding about the profession and the confusion between psychologists and psychiatrists (Farberman, 1997; Firmin et al., 2012; von Sydow \& Reimer, 1998). This confusion often leads to negative stereotyping and prejudice about psychologists.

In general, the public image of psychiatrists is negative (Sartorius et al., 2010). The perception of stigma, negative stereotypes, and prejudice is a major problem that requires implementation of relevant projects, as well as detailed 
exploration of the topic in order to find more effective solutions. Largely responsible for creation and maintenance of the negative public image of mental health professionals is media (Gharaibeh, 2005). For most people psychiatrists are not the profession with whom they often come in contact. Therefore, the media, for example, movies, play a critical role in developing public perceptions (e.g., Gharaibeh, 2005).

There is a lack of research focusing on gender and age group differences in stereotypes about mental health professionals. Previous findings show that men and women rate characteristics of psychiatrists, psychologists, and counsellors similarly (Bremer et al., 2001). But other scientists have found that women perceive health professionals as more supportive than men perceive (Ostlund, Borg, Wide, Hensing, \& Alexanderson, 2003). In general, women, compared to men, have a more positive attitudes toward seeking professional help (Chang, 2007; Mackenzie, Gekoski, \& Knox 2006; ten Have et al., 2010; Nam et al., 2010). The negative attitudes toward seeking professional help that men hold, were found to be associated with masculinity norms (Levant, Wimer, Williams, Smalley, \& Noronha, 2009). Endorsement of traditional gender role stereotypes decreases men's help-seeking intentions. Interestingly, in France women prefer to seek help from psychologists, whereas men prefer to seek help from psychiatrists (Kovess-Masféty et al., 2007). The authors concluded that perhaps women might prefer to talk about their problems, while men choose a medical approach. However, this topic is still unclear and thus, more research is required.

Some studies have shown that people are more likely to seek psychological help from general practitioners (GPS) over mental health professionals (Dupree, Herrera, Tyson, Jang, \& King-Kallimanis, 2010; Kovess-Masféty et al., 2007; Rickwood, Deane, Wilson, \& Ciarrochi, 2005); this is especially true for older adults (Dupree, et al., 2010; KovessMasféty et al., 2007; Mackenzie, et al., 2006). One duty of GPs is to refer patients to other specialists. Based on that, GPs are the gatekeepers to mental health care. People may seek help from GPs because they are associated with fewer stigmas compared to mental health professionals. Despite that, there is little research regarding public attitudes toward GPs/primary care physicians/family doctors; therefore new research is needed. Previous studies have outlined both positive and negative aspects of public stereotypes; generally, positive views were found more than negative (Conroy et al., 2002; Marcinowicz, Chlabicz, \& Grebowski, 2009).

An alternative mental health care provider is a member of the clergy. Religious individuals have more positive attitudes and intention to seek help from members of the faith community more so than do non-religious individuals (Smith \& Simmonds, 2006). There are a few empirical studies regarding stereotypes towards religious professions. These findings show that in general Christian clergy are perceived positively, and described as friendly, helpful, and compassionate (Asuncion \& Mackie, 1996; Johnstone, 1972). It should also be noted that clergy represent a number of different religions therefore warmth stereotypes cannot be straightforwardly applied for all types of clergy.

As mentioned before, people may prefer different professions in the case of mental health problems. One popular profession is astrologers (e.g., Furnham, 2000; Moodley \& Sutherland, 2010). Despite the fact that astrology is not a science, many people count it as a science (Kallery, 2001; De Robertis \& Delaney, 1993). The confusion between astrology and astronomy helps maintains these false beliefs. Individuals, who accept supernatural beliefs, are more willing to seek help from professionals of these beliefs (Smith \& Simmonds, 2006). Because much of the public believe in some kind of astrological principles (Kallery, 2001; Rice, 2003; De Robertis \& Delaney, 1993), there is a need to explore attitudes toward this profession. For example, the results from a national survey in the USA show that $33.3 \%$ of the respondents believe in astrology (Rice, 2003). Torgler (2007) has found a high degree of superstition in formerly Communist countries, including Latvia. Many researchers point out that women are more likely than men to believe in supernatural beliefs (Baker \& Draper, 2010; Rice, 2003; Torgler, 2007), among them astrology (Rice, 2003). Moreover, younger people are more superstitious compared to older people (Torgler, 2007). Based on previous research, women and younger adults may have more positive stereotypes about astrologers.

Comparing stereotypes about mental health care providers, previous studies show that psychologists (including counsellors) and clergy are described more often with warmth related characteristics, whereas psychiatrists are perceived more often as cold, but competent (Schindler, Berren, Hannah, Beigel, \& Santiago, 1987; von Sydow \& Reimer, 1998; Wollersheim \& Walsh, 1993). Higher status and prestige is attributed more to doctors than other helping professions (Schindler et al., 1987; von Sydow \& Reimer, 1998). Older adults in particular prefer to seek psychological help from GPs compared to younger adults who prefer seeking help from mental health professionals (Dupree, et al., 2010; Kovess-Masféty et al., 2007; Mackenzie, et al., 2006). These findings suggest that older people may hold more negative stereotypes about mental health professionals and more positive stereotypes about family doctors. Across the world women have more positive intentions to seek help for mental health problems (Chang, 2007; Mackenzie et al., 2006; ten Have et al., 2010; Nam et al., 2010). Accordingly, women may hold more positive stereotypes about all helping professionals. However, these are only assumptions; there is a lack of research available to answer which of 
demographic groups held more negative or more positive stereotypes about helping professionals.

\section{Method}

\subsection{Participants}

The data were collected over the Internet from 338 participants, aged 18 to 87 ( $M=41.01$ years, $S D=16.25)$. There were $180(53.3 \%)$ women $(M=38.12$ years, $S D=16.57)$ and $158(46.7 \%)$ men $(M=44.30$ years, $S D=15.27)$. Of the participants, $36.4 \%(n=123)$ were age 50 and above and 63.6\% $(n=215)$ age 18 to 49 . The younger adult group $(<50)$ had a mean age of 30.56 years $(S D=8.97)$ and older adult group $(49<)$ had a mean age of 59.28 years $(S D=7.70)$. In terms of education, $62.7 \%$ of participants had 14 or more years of schooling, $34.9 \%$ had 10 to 13 years and $2.4 \%$ had 9 years of schooling. In terms of marital status, $44.3 \%$ of participants were not married, $37.3 \%$ were married, and $18.3 \%$ were previously married. In terms of religious affiliation, $43.2 \%$ were Christians, $7.4 \%$ had other religious affiliation, $36.4 \%$ were not religious, and $13.0 \%$ did not respond to the question. All participants were Latvian-speaking adults.

\subsection{Materials}

A modified version of the stereotype content model (SCM) was used to measure profession stereotypes (Fiske, $\mathrm{Xu}$, Cuddy, \& Glick, 1999). According to this model stereotypes can be divided in two fundamental dimensions: warmth and competence. SCM has been widely used exploring stereotypes of different kind of groups, among them professions (Brambilla et al., 2010; Carlsson \& Bjorklund, 2010; Cuddy, Fiske, \& Glick, 2004). Previous studies have proven high validity and reliability of this instrument (e.g., Cuddy et al., 2009; Fiske, Cuddy, Glick, \& Xu, 2002).

In the current study participants rated five typical professionals (a family doctor, a psychiatrist, a psychologist, a clergyperson, and an astrologer) on warmth and competence scales. Items were borrowed from previous research (Fiske et al., 2002; Russel \& Fiske, 2008) and translated into Latvian. The warmth factor included four items: warm, kind, trustworthy, and well-intentioned. The competence factor included four items: competent, skilful, capable, and intelligent. Using 7-point Likert-type scale (1=not at all to $6=$ =xtremely; 7=cannot tell) participants rated each of the professions on warmth and competence. In the original version of the questionnaire participants were asked to think about how the groups are viewed by society. We changed this instruction to "Regardless of whether you have visited or not, evaluate what you think of a typical family doctor/a psychiatrist/a psychologist/a clergyperson/an astrologer." We also provided short definitions of these professions to avoid the possible confusions.

\subsection{Procedure}

The stereotype ratings were conducted as a part of a larger research project. Data were collected through an internet site without any time limitation. First, participants were introduced to the research. Second, they rated stereotypic characteristics of the five professionals. The sequence of professionals was counterbalanced across the participants. Finally, participants entered demographic information and were thanked for their participation. We offered no participation incentives.

\section{Results}

We needed to construct common and reliable scales for all 5 groups that also worked for each group separately. Based on previous SCM research (Fiske et al., 1999; Fiske et al., 2002; Russell \& Fiske, 2008), 5 separated analyses were calculated (one per profession). A principal component analysis with oblimin rotation (delta $=-10$ ) was used. Items that overlapped competence and warmth or loaded on different scales across professions were removed from the study. Warm and kind loaded onto warmth, and competent, skilful and capable loaded onto competence. Modified SCM scales accounted for $84.1-86.0 \%$ of the variance. Warmth items loaded from .59 to .98 , and competence items loaded from .71 to .99 . Reliabilities for warmth scale were from alpha .78 to .87 , and .88 to .92 for competence scale.

Our primary interest was to determine whether warmth and competence stereotypes differed as a function of participant gender and age group. We used Mann-Whitney $U$ tests with gender, and age as between-participants variables. Missing values ranged from 1 to 37 , and cases were excluded test by test.

Gender differences show that women rate a typical psychiatrist higher on warmth $(U=9399.00, p<.01)$ and 
competence $(U=8899.50, p<.001)$. Women also rate a typical psychologist $(U=10581.00, p<.05)$, a clergyperson $(U$ $=9816.50, p<.05)$, and an astrologer $(U=9882.00, p<.05)$ higher on competence. The results are depicted in Table 1.

Table 1. Gender differences in stereotypes about helping professionals

\begin{tabular}{|c|c|c|c|c|c|c|}
\hline & \multicolumn{4}{|c|}{ Gender } & \multirow{3}{*}{ U } & \multirow[b]{3}{*}{$p$} \\
\hline & \multicolumn{2}{|c|}{ Women $(n=180)$} & \multicolumn{2}{|c|}{$\operatorname{Men}(n=158)$} & & \\
\hline & $M$ & $S D$ & $M$ & $S D$ & & \\
\hline \multicolumn{7}{|l|}{ Warmth } \\
\hline a family doctor & 4.07 & 1.07 & 4.11 & 1.11 & 13967.50 & .844 \\
\hline a psychiatrist & 4.19 & 1.05 & 3.77 & 1.11 & $9399.00^{\star \star}$ & .001 \\
\hline a psychologist & 4.43 & .91 & 4.19 & 1.10 & 11252.00 & .069 \\
\hline a clergyman & 4.61 & .93 & 4.50 & 1.09 & 11697.50 & .278 \\
\hline an astrologer & 4.19 & 1.02 & 4.00 & 1.11 & 10361.00 & .226 \\
\hline \multicolumn{7}{|l|}{ Competence } \\
\hline a family doctor & 4.31 & .93 & 4.24 & 1.02 & 13251.00 & .575 \\
\hline a psychiatrist & 4.53 & .91 & 4.12 & 1.02 & $8899.50^{\star \star \star}$ & .000 \\
\hline a psychologist & 4.41 & 1.00 & 4.18 & 1.05 & $10581.00^{*}$ & .037 \\
\hline a clergyman & 4.52 & .94 & 4.21 & 1.12 & $9816.50^{\star}$ & .010 \\
\hline an astrologer & 4.20 & 1.12 & 3.89 & 1.21 & $9882.00^{\star}$ & .033 \\
\hline
\end{tabular}

Age group differences show that older adults (ages ranging from 50 to 87$)$ rate a psychiatrist $(U=9340.00, p<.05)$ and a psychologist $(U=9428.00, p<.01)$ lower on warmth. They also rate a psychiatrist $(U=8288.50, p<.01)$ and a psychologist $(U=8619.00, p<.001)$ lower on competence, but a family doctor higher on competence $(U=11102.50, p<$ .05). The results are depicted in Table 2.

Table 2. Age group differences in stereotypes about helping professionals

\begin{tabular}{|c|c|c|c|c|c|c|}
\hline & \multicolumn{4}{|c|}{ Age group } & \multirow[b]{3}{*}{$U$} & \multirow[b]{3}{*}{$p$} \\
\hline & \multicolumn{2}{|c|}{ Younger adults $(n=215)$} & \multicolumn{2}{|c|}{ Older adults $(n=123)$} & & \\
\hline & $M$ & $S D$ & $M$ & $S D$ & & \\
\hline \multicolumn{7}{|l|}{ Warmth } \\
\hline a family doctor & 4.03 & 1.09 & 4.20 & 1.08 & 12106.50 & .216 \\
\hline a psychiatrist & 4.09 & 1.11 & 3.82 & 1.05 & $9340.00 *$ & .019 \\
\hline a psychologist & 4.45 & 1.00 & 4.09 & .98 & $9428.00^{\star *}$ & .002 \\
\hline a clergyman & 4.64 & .98 & 4.41 & 1.04 & 10209.00 & .066 \\
\hline an astrologer & 4.15 & 1.04 & 4.03 & 1.11 & 9923.00 & .358 \\
\hline \multicolumn{7}{|l|}{ Competence } \\
\hline a family doctor & 4.19 & .92 & 4.43 & 1.05 & $11102.50^{\star}$ & .041 \\
\hline a psychiatrist & 4.46 & .98 & 4.13 & .96 & 8288.50 ** & .001 \\
\hline a psychologist & 4.44 & 1.04 & 4.06 & .96 & $8619.00 * \star \star$ & .000 \\
\hline a clergyman & 4.45 & 1.04 & 4.24 & 1.02 & 9624.50 & .070 \\
\hline an astrologer & 4.12 & 1.18 & 3.94 & 1.15 & 9660.00 & .152 \\
\hline
\end{tabular}

${ }^{\star} p<.05,{ }^{* \star} p<.01,{ }^{* \star *} p<.001$

\section{Discussion}

The present study explored gender and age group differences in stereotypes about mental health care providers. This topic is very important in explaining attitudes toward mental health care providers based on the fact that mental health care services are underutilised across the world, especially among men and older adults. According to previous studies, the role of demographics in stereotypes of helping professionals is unclear.

Analysis of the differences between men and women show that women rate a typical psychiatrist higher on warmth and competence, and a psychologist higher on competence. Women across the world held more positive attitudes toward seeking help from mental health professionals than did men (Chang, 2007; Mackenzie et al., 2006; ten Have et al., 2010; Nam et al., 2010). The results reveal that negative stereotypes about psychiatrists - who are perceived as being cold - are held more by men, who are also more sceptical about the competence of mental health professionals. Therefore, stereotypes about psychologists and psychiatrists may explain why men have lower intentions of seeking 
professional mental health services.

In this study women rated a clergyperson and an astrologer higher on competence than did men. Previous research has found that women tend to be more likely to believe in supernatural beliefs (Baker \& Draper, 2010; Rice, 2003; Torgler, 2007). Evidently, women use more helping services, and they are more open to visit a wide range of mental health care providers.

Analysis with older and younger adult groups shows that older adults rate a typical family doctor higher on competence, whereas a psychiatrist and a psychologist lower on competence and lower on warmth. These findings are in the line with research on help-seeking attitudes, and provide a possible explanation of the underutilisation of mental health care in older adults. Older adults prefer to seek mental health care from family doctors, whereas younger adults are more positive about psychologists and psychiatrists (Dupree et al., 2010; Kovess-Masféty et al., 2007; Mackenzie et al., 2006). Seeking family doctors for mental health problems could be seen positively if patients are referred to psychiatrists or psychologists. This may require education of family doctors about mental health problems. More positive stereotypes about psychologists and psychiatrists in younger group are explained with better education and possible experience with these professionals (e.g., school psychologists, a wide range of materials in the internet).

The results found in this study should be seen in a cultural context, but they are not representative of Latvia. In Latvia, before 1993, there were no more than 40 psychologists (Renge, 2003). Despite the rapid growth in the count of psychologists in following years, psychology is still misunderstood as a science (Renge \& Austers, 2004). In Latvia, compared to older European Union countries, psychologists are still fighting for their position, which may result in more negative overall stereotype ratings, especially among older adults. In the current study, a large number of participants counted themselves as Christians; thus, they indicated a heightened rating of members of the clergy. Respondents were generally well-educated; therefore the data of a representative sample could differ.

The present research is the first to explore gender and age group differences in stereotypes about mental health care providers through the use of well-established warmth and competence scales. The outcomes contribute to the literature on attitudes towards mental health professionals. Continuing research in stereotypes about mental health care providers is very necessary. Representative cross-cultured studies are required. Increasing the utilisation of mental health care requires education of men and older adults, and improvement of health care policy.

\section{Acknowledgement}

This work has been supported by the European Social Fund within the project «Support for Doctoral Studies at University of Latvia».

\section{References}

Asuncion, A. G., \& Mackie, D. M. (1996). Undermining social stereotypes: Impact of affect-relevant and behavior relevant information. Basic and Applied Social Psychology, 18, 367-386.

Baker, J. O, \& Draper, S. (2010). Diverse supernatural portfolios: Certitude, exclusivity, and the curvilinear relationship between religiosity and paranormal beliefs. Journal for the Scientific Study of Religion, 49(3), 413-424.

Brambilla, M., Sacchi, S., Castellini, F., \& Riva, P. (2010). The effects of status on perceived warmth and competence: Malleability of the relationship between status and stereotype content. Social Psychology, 41, 82-87.

Bremer, B. A., Foxx, R. M., Lee, M., Lykins, D., Mintz, V. R., \& Stine, E. (2001). Potential clients' beliefs about the relative competency and caring of psychologists: Implications for the profession. Journal of Clinical Psychology, 57, 1479-1488.

Carlsson, R., \& Bjorklund, F. (2010). Implicit stereotype content: Mixed stereotypes can be measured with the implicit association test. Social Psychology, 41, 213-222.

Chang, H. (2007). Psychological distress and help-seeking among Taiwanese college students: role of gender and student status. British Journal of Guidance \& Counselling, 35, 347-355.

Conroy, R. M., Teehan, M., Siriwardena, R., Smyth, O., McGee, H. M., \& Fernandes, P. (2002). Attitudes to doctors and medicine: The effect of setting and doctor - patient relationship. British Journal of Health Psychology, 7, 117-125.

Cox, W. T. L., Abramson, L. Y., Devine, P. G., \& Hollon, S. D. (2012). Stereotypes, prejudice, and depression: The integrated perspective. Perspectives on Psychological Science, 7, 427-449.

Cuddy, A. J. C., Fiske, S. T., \& Glick, P. (2004). When professionals become mothers, warmth doesn't cut the ice. Journal of Social Issues, 60, 701-718.

Cuddy, A. J. C., Fiske, S. T., \& Glick, P. (2007). The BIAS map: Behaviors from intergroup affect and stereotypes. Journal of Personality and Social Psychology, 92, 631-648.

Cuddy, A. J. C., Fiske, S. T., Kwan, V. S. Y., Glick, P., Demoulin, S., Leyens, J-P., Bond, M. H., Croizet, J-C., Ellemers, N., Sleebos, E., Htun T. T., Kim, H-J., Maio, G., Perry, J., Petkova, K., Todorov, V., Rodriguez-Bailon, R., Morales, E., Moya, M., Palacios, M., Smith, V., Perez, R., Vala, J., \& Ziegler, R. (2009). Stereotype content model across cultures: Towards universal similarities and some differences. British Journal of Social Psychology, 48, 1-33. 
De Robertis, M. M., \& Delaney, P. A. (1993). A survey of the attitudes of university students to astrology and astronomy. Journal of the Royal Astronomical Society of Canada, 87(1).

Dupree, L. W., Herrera, J. R., Tyson, D. M., Jang, Y., \& King-Kallimanis, B. L. (2009). Age group differences in mental health care preferences and barriers among Latinos: Implications for research and practice. Best Practices in Mental Health, 6, 47-59.

Farberman, R. K. (1997). Public attitudes about psychologists and mental health care: Research to guide the American Psychological Association public education campaign. Professional Psychology: Research and Practice, 28, 128-136.

Firmin, M. W., Wantz, R. A., Holmes, H. J., Stoltzfus, M., Ray, B. N., \& Geib, E. F. (2012). Undergraduate college students' perceptions of psychologists. North American Journal of Psychology, 14(2), 371-382.

Fiske, S. T., Xu, J., Cuddy, A. C., \& Glick, P. (1999). (Dis)respecting versus (dis)liking: Status and interdependence predict ambivalent stereotypes of competence and warmth. Journal of Social Issues, 55, 473-491.

Fiske, S. T., Cuddy, A. J. C., Glick, P., \& Xu, J. (2002). A model of (often mixed) stereotype content: Competence and warmth respectively follow from perceived status and competition. Journal of Personality and Social Psychology, 82, 878-902.

Fiske, S. T. (2012). Warmth and competence: Stereotype content issues for clinicians and researchers. Canadian Psychology, 53, 14-20.

Furnham, A. (2000). The perceived efficacy of various "future-ologies" and complementary medicine. The Journal of Alternative and Complementary Medicine, 6, 71-76.

Gharaibeh, N. M. (2005). The psychiatrist's image in commercially available American movies. Acta Psychiatrica Scandinavica, 111, 316-319.

Johnstone, R. L. (1972). Public images of protestant ministers and catholic priests: An empirical study of anti-clericalism in the U.S. Sociology of Religion, 33(1), 34-49.

Kallery, M. (2001). Early-years educators' attitudes to science and pseudo-science: The case of astronomy and astrology. European Journal of Teacher Education, 24(3), 229-242.

Kovess-Masféty, V., Saragoussi, D., Sevilla-Dedieu, C., Gilbert, F., Suchocka, A., Arveiller, N., Gasquet, I., Younes, N., \& Hardy-Bayle, M-C. (2007). What makes people decide who to turn to when faced with a mental health problem? Results from a French survey. BMC Public Health, 7:188.

Levant, R. F., Wimer, D. J., Williams, C. M., Smalley, K. B., \& Noronha, D. (2009). The relationships between masculinity variables, health risk behaviors and attitudes toward seeking psychological help. International Journal of Men's Health, 8, 3-21.

Lipton, J., O'Connor, M., Terry, C., \& Bellamy, E. (1991). Neutral job titles and occupational stereotypes: When legal and psychological realities conflict. Journal of Psychology, 125 (2), 129-151.

Mackenzie, C. S., Gekoski, W. L., \& Knox, V. J. (2006). Age, gender, and the underutilization of mental health services: The influence of helpseeking attitudes. Aging \& Mental Health, 10, 574-582.

Marcinowicz, L., Chlabicz, S., \& Grebowski, R. (2009). Patient satisfaction with healthcare provided by family doctors: Primary dimensions and an attempt at typology. BMC Health Services Research, 9:63.

Moodley, R., \& Sutherland, P. (2010). Psychic retreats in other places: Clients who seek healing with traditional healers and psychotherapists. Counselling Psychology Quarterly, 23, 267-282.

Nam, S. K., Chu, H. J., Lee, M. K., Lee, J. K., Kim, N., \& Lee, S. M. (2010). A meta-analysis of gender differences in attitudes toward seeking professional psychological help. Journal of American College Health, 59,110-116.

Ostlund, G. M., Borg, K. E., Wide, P., Hensing, G. K.E., \& Alexanderson, K. A. E. (2003). Clients' perceptions of contact with professionals within healthcare and social insurance offices. Scandinavian Journal of Public Health, 31, 275-283.

Plous, S. (2003). The psychology of prejudice, stereotyping, and discrimination: An overview. In S. Plous (Ed.), Understanding Prejudice and Discrimination (pp. 3-48). New York: McGraw-Hill.

Renge, V. (2003). Development of the science of psychology in Latvia after regaining of independence. Baltic Journal of Psychology, 4(1), 5-14.

Renge, V., \& Austers, I. (2004). Social representations of science and psychology: Anchoring and personification. Baltic Journal of Psychology, 5 , $5-13$.

Rice, T. W. (2003). Believe it or not: Religious and other paranormal beliefs in the United States. Journal for the Scientific Study of Religion, 42:1, 95-106.

Rickwood, D., Deane, F. P., Wilson, C., \& Ciarrochi, J. (2005). Young people's help-seeking for mental health problems. Australian e-Journal for the Advancement of Mental Health, 4(3) Supplement.

Russell, A. M. T, \& Fiske, S. T. (2008). It's all relative: Competition and status drive interpersonal perception. European Journal of Social Psychology, 38, 1193-1201.

Sartorius, N., Gaebel, W., Cleveland, H-R., Stuart, H., Akiyama, T., Arboleda-Florez, J., Baumann, A. J., Gureje, O., Jorge, M. R., Kastrup, M., Suzuki, Y., \& Tasman, A., (2010), WPA guidance on how to combat stigmatization of psychiatry and psychiatrists. WPA guidance papers. [Online] Available: http://www.wpanet.org/detail.php?section_id=7\&content_id=922 (March 3, 2013)

Schindler, F., Berren, M. R., Hannah, M. T., Beigel, A., \& Santiago, J. M. (19̄87). How the public perceives psychiatrists, psychologists, nonpsychiatric physicians, and members of the clergy. Professional Psychology: Research and Practice, 18, 371-376.

Sherman, J. W. (1996). Development and mental representation of stereotypes. Journal of. Personality and Social Psychology, 70, $1126-1141$.

Smith, A. F., \& Simmonds, J. G. (2006). Help-seeking and paranormal beliefs in adherents of mainstream religion, alternative religion, and no religion. Counselling Psychology Quarterly, 19 (4), 331-341.

ten Have, M., de Graaf, R., Ormel, J., Vilagut, G., Kovess, V., \& Alonso, J. (2010). Are attitudes towards mental health help-seeking associated with service use? Results from the European study of epidemiology of mental disorders. Social Psychiatry and Psychiatric Epidemiology, 45, 153-163.

Torgler, B. (2007). Determinants of superstition. Journal of Socio-Economics, 36, 713-733.

von Sydow, K., \& Reimer, C. (1998). Attitudes toward psychotherapists, psychologists, psychiatrists, and psychoanalysts. A meta-content analysis of 60 studies published between 1948 and 1995. American Journal of Psychotherapy, 52, 463-488.

Wollersheim, D. M., \& Walsh, J. A. (1993). Clinical psychologists: Professionals without a role? Professional Psychology: Research and Practice, 24, 171-175. 